\title{
Campo interdisciplinar da ciência da informação: fronteiras remotas e recentes
}

\author{
Lena Vania Ribeiro Pinheiro \\ Deparatmento de Ensino e Pesquisa \\ Programa de Pos-Graduaçao en Ciencia da Informaçao \\ Av. Venceslao Bras, 71-Pavilhao Mario de Almeida, \\ Rio de Janeiro- RJ-22290-140 Rio de Janeiro, Brasil.
}

\begin{abstract}
RESUMEN
Este artículo se origina a partir de la discusión sobreel grado de profundidad de los conceptos, nociones y definiciones de la Ciencia de la Información, en aspectos de su historia, terreno conceptual, campo científico e interdisciplinariedad. Se inserta directa y fuertemente en la corriente de Epistemología histórica, que busca dilucidar la producción de teorías y de los conceptos científicos a partir de un análisis de la propia historia de las ciencias, de sus resolucionesy de las demarcaciones (“dámarches") del espíritu científico tomando como fundamento sobre todo las ideas de Bachelrad, dialectizando nociones fundamentales, manteniendo en discusión los resultados adquiridos, "en acción polémica incesante de la razón" que caracteriza la "actividad constructiva de la filosofía de la negación."
\end{abstract}

\section{INTERDISCIPLINARY FIELDSIN INFORMATION SCIENCE: PAST AND RECENT FRONTIERS Lena Vania Ribeiro-Pinheiro}

This article has its origins in the discussion of the degree of profundity in the concepts, notions and definitions of Information Science, in aspects of its history, conceptual scope, scientific field and its interdisciplinary nature. These are inserted directly and forcibly into the trends of Historical Epistemology which look to elucidate the production of scientific theory and concepts based on an analysis of the history of the sciences, of their resolutions and demarcations of the scientific spirit. Above all, the ideas of Bachelrad are taken as the foundation, arguing the basic notions, maintaining in discourse the acquired results "in incessant and polemic action of reason" which characterizes the "constructive activity of the philosophy of negation."

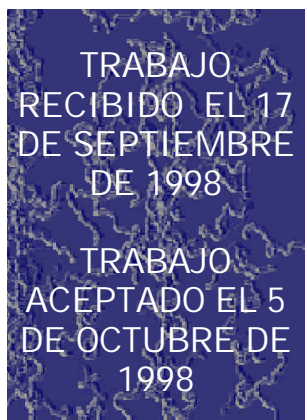




\section{INTRODUÇÃ O}

Q uando em 1982 apresentamos dissertação de mestrado em Ciência da Informação, propondo uma reformulação conceitual da Lei de Bradford, a grande questão que ficou em aberto foi se uma lei, originalmente formulada para informação gerada numa área como a G eofísica Aplicada e Lubrificação, teria validade ou poderia chegar aos mesmos resultados em informação de outros campos do conhecimento como Medicina, Engenharia e Filosofia, se as ciências têm suas similaridades mas diferem, substancialmente, na sua natureza, processos, teorias e metodologias? E, além disso, como tratar uma ciência social cujo objeto, informação, é produzido pelo homem e também por ele absorvido, num ciclo autofágico, dinâmico e singular? Se este homem faz parte de comunidades científicas com padrões específicos de comunicação e busca de informação e cânones próprios na estrutura da literatura, decorrência natural da essência e "etnografia" de cada campo do conhecimento? Ou se o indivíduo, parte integrante de uma determinada cultura e circunstâncias educacionais, sociais, políticas e históricas bem definidas reage aos estímulos de informação de acordo com esses fatores determinantes?

Durante vinte anos de estudos de Ciência da Informação, nossa percepção é de que a Ciência da Informação tem seu próprio estatuto científico, como ciência social que é, portanto, interdisciplinar por natureza, e apresenta interfaces com a Biblioteconomia, Ciência da Computação, Ciência Cognitiva, Sociologia da Ciência e Comunicação, entre outras áreas, e suas raízes, em princípio, vêm da bifurcação da D ocumentação/ Bibliografia e da Recuperação da Informação. E seu objeto de estudo, por si mesmo, na complexidade de categoria abstrata, é de difícil apreensão.

A partir da discussão sobre o grau de profundidade dos conceitos, noções e definições da Ciência da Informação, em aspectos de sua história, terreno conceitual, campo científico e interdisciplinaridade, o que foi questionado, em pesquisa de doutorado(Pinheiro,1997), teve como pano de fundo a Filosofia da Ciência, num primeiro momento, e a Epistemologia, no segundo, ambas estreitamente interligadas. Portanto, a tese da qual se origina este artigo - correspondendo a um de seus capítulos, com as necessárias adaptações-, se insere, mais direta e fortemente, na corrente de Epistemologia histórica, que busca elucidar a produção de teorias e dos conceitos científicos a partir de uma análise da própria história das ciências, de suas resoluções e das "démarches" do espírito científico(Japiassu,1977, p.65), tomando como fundamento sobretudo as idéias de Bachelard(1987, p. 136), dialetizando noções fundamentais, mantendo em discussão os resultados adquiridos, "na ação polêmica incessante da razão" que caracteriza a "atividade construtiva da filosofia do não".

Assim, as inquietações sobre as quais a pesquisa se debruçou vão desde a gênese da Ciência da Informação, a natureza dos fenômenos observados, descritos e explicados, seu corpo de conhecimentos, definições e conceitos, suas leis e teorias, en- 


\section{InvesigaaónBiblictedóǵạ v. 12 No. 25 julio/ diciembre de 1998}

fim, o conjunto de elementos que a caracterizam como campo do conhecimento, naquilo que chamamos delimitações internas. Complementam o estudo as delimitações externas, como um olhar da ciência da Informação sobre si mesma, perceptível através de manifestações tais como periódicos, sociedades e eventos técnico-científicos e sua produção intelectual, principalmente pesquisas em Ciência da Informação.

Essas preocupações têm sua continuidade no aprofundamento das interfaces da Ciência da Informação com outras áreas, objeto deste artigo.

Um dos pressupostos da tese foi o da Ciência da Informação como ciência social, tendo o seu objeto de estudo -informação- , produto do homem, inscrito em diferentes contextos, seja científico, tecnológico, educacional, político, artístico e cultural, inicialmente mais associado à ciência.

A diversidade de conteúdos é a mesma de forma, isto é, o processo de comunicação se concretiza através dos mais diversos canais, tangíveis e intangíveis, orais, manuscritos, impressos ou eletrônicos. O bjetos e fatos criados e promovidos pelo homem, por exemplo, contêm informação e fogem às categorias tradicionais de documento.

O âmago da pesquisa é traduzido no subtítulo da tese -domínio epistemológico e campo interdisciplinar- estreita e profundamente associados, daí ser impossível, neste artigo, centrado na interdisciplinaridade, deixar de enfocar alguns resultados da pesquisa, no seu conjunto, principalmente os relacionados à constituição da Ciência da Informação como campo do conhecimento, ou melhor, o continente Ciência da Informação e seus conteúdos disciplinares. Para esta delimitação de território disciplinar foi adotado como fonte para a pesquisa empírica o Annual Review of Information Science and Technology-ARIST. Assim, disciplinas constituintes da Ciência da Informação são desdobradas até sua interdisciplinaridade, reunidas e articuladas entre si, de tal forma a refletir esta ciência no mundo contemporâneo, nas suas características sócio-culturais e tecnológicas.

E, para ilustrar a interdisciplinaridade como componente de um campo do conhecimento, o pensamento de Foskett: "uma nova disciplina não surge simplesmente porque velhos praticantes se desempenham melhor em seus empregos, mas porque dinamicamente novas relações aparecem com outros campos" p.15)

\section{BREVE TRAÇADO DA EV OLUÇÃ O CONCEITUAL DA CIÊNCIA DA IN FO RMAÇÃ O}

O estudo da Ciência da Informação parte do reconhecimento de sua interdisciplinaridade, de sua natureza social, forte e profundamente relacionada à tecnologia da informação e do novo papel da informação na sociedade e cultura contemporâneas, características essenciais da área, ressaltadas por Saracevic:

natureza interdisciplinar, mudança nas relações com outras disciplinas e perspectiva de longa duração da evolução da interdisciplinaridade; 
* conexão inexorável à tecnologia da informação; e

* participação ativa e deliberada na evolução da sociedade da informação, assim como outras áreas.(Saracevic, 1992, p.6)

A abordagem interdisciplinar pressupõe um conceito de Ciência da Informação, daí esta síntese conceitual, de forma evolutiva.

Uma das primeiras definições é de Taylor(1966), posteriormente sintetizada e reelaborada por Borko(1968, p.3), em definitivo artigo em tomo do que seria Ciência da Informação: "disciplina que investiga as propriedades e comportamento da informação, as forças que regem o fluxo de informação, a fim de alcançar acessibilidade e utilização ótimas". A nova área foi por ele compreendida como um corpo de conhecimentos relacionados "à origem, coleção, organização, armazenagem, recuperação, interpretação, transmissão, transformação e utilização da informação".

Até então, os especialistas estão mais preocupados com o processo em si, e não com os impactos da informação no homem e na sociedade, mais evidenciados, nessa fase, na antiga União Soviética, onde Ciência da Informação é denominada Informática.

Ao abordar o fenômeno informação, Mikhailov, Chernyi e Gilyarevskyi(1969, p.14) afirmam que a sua substância "são processos, métodos e leis relativos ao registro, processamento sintético-analítico, armazenamento, recuperação e disseminação da informação", e esclarecem que não se trata de "[...] informação científica tal qual atributo de uma respectiva ciência ou disciplina", e sim aquela "usada, no caso, para significar a informação lógica obtida no processo de cognição que adequadamente reflete leis do mundo material e atividades espirituais de experiência humana e é utilizada na prática sócio -histórica".

Algumas definições, como a de Foskett(1980), trazem implícitas relações interdisciplinares, pois Ciência da Informação é uma "disciplina que surge de uma fertilização cruzada de idéias que incluem a velha arte da Biblioteconomia, a nova arte da Computação, as artes dos novos meios de comunicação, e aquelas ciências como a Psicologia e Lingǘstica, que em suas formas modernas têm a ver diretamente com todos os problemas da comunicação - a transferência do pensamento organizado".

Em relevante trabalho, principalmente pela relação entre informação e conhecimento, Belkin e Robertson(1976, p.192) assim se manifestam:

Ciência da Informação é uma disciplina orientada a problema relacionado com a efetiva transferência de informação desejada, do gerador humano para o usuário humano, e aúnica noção comum a todos os conceitosé a de mudança de estrutura.

Ao estudar o pensamento de Brookes(1975), grande teórico da área e por ele considerado o "protagonista mais formidável" da corrente de pensamento da Ciência da Informação como manifestação social, Roberts(1976) ressalta que 0 fenômeno não pode ser estudado de forma isolada, mas parte de um processo 


\section{Invesigaaón Biblideedógica v. 12 No. 25 julio/ diciembre de 1998}

contínuo. Este é um esforço que requer "o estudo objetivo do conhecimento, não somente como um fenômeno cognitivo mas também como fenômeno social peculiar para a evolução do homem".

0 próprio Brookes publica, no Jaumal of Information Saience, denso trabalho sobre os fundamentos da Ciência da Informação, numa série de quatro artigos, abordando aspectos filosóficos e mudanças de paradigmas da área, enfatizando algumas distinções com outras áreas:

[...]a tarefa da Ciência da Informação pode ser definida como a explicação do mundo do conhecimento objetivo, como uma extensão de, mas diferente do mundo da Documentação e Biblioteconomia(Brookes, 1980, part I).

$\mathrm{Na}$ análise da Ciência da Informação como Ciência Social, Brookes destaca as dificuldades das Ciências Sociais em superar a separação de efeitos objetivos de efeitos subjetivos, daí a "responsabilidade especial" da Ciência da Informação

Tendo por fundamento as idéias de Popper, sobretudo o mundo do conhecimento humano, esse teórico vislumbra importante papel da Ciência da Informação, ainda não reivindicado por nenhuma outra área, na relação de informação e conhecimento, assim como a liderança da tecnologia da informação no processo de desenvolvimento da área (1980-81, part I, II,III e IV).

O pensamento contemporâneo pode ser sintetizado pelas idéias de dois grandes teóricos da área, um deles já mencionado, Saracevic (1992), e Wersig (1993). Ambos têm presença decisiva na Ciência da Informação desde o seu aparecimento e discussões iniciais, na sua contribuição para a estrutura teórica e avanços desse novo campo do conhecimento.

Tefko Saracevic foi quem melhor elaborou o conceito de relevância, atribuindo à recuperação da informação a causa maior do surgimento da Ciência da Informação e influência na indústria da informação. Hoje, a Ciência da Informação transcende a própria recuperação, presente ainda no seu núcleo, evoluiu, e sua base, atualmente, "está relacionada com os processos de comunicação humana".

Uma das mais recentes definições de Ciência da Informação de Saracevic reflete essa evolução, no reconhecimento da Ciência da Informação como:

[...] campo devotado à investigação científica e prática profissional que trata dos problemas de efetiva comunicação de conhecimentos e de registros do conhecimento entre seres humanos, no contexto de usos e necessidades sociais, institucionais e/ ou individuais de informação. No tratamento desses problemas tem interesse particular em usufruir, 0 mais possível, da moderna tecnologia da informação. (1992).

Wersig (1993) considera a Ciência da Informação um protótipo de ciência pósmoderna, ao lado da Ecologia. Portanto, não é uma ciência clássica e a sua emergência decorre da necessidade de estratégias para solução de problemas causados pela ciência e tecnologia. 0 cerne da questão é a mudança revolucionária do papel do conhecimento, no mundo contemporâneo, tanto em dimensões filosóficas quanto tecnológicas, o que se inicia, segundo ele, na década de 60. 
Wersig questiona se os novos tipos de disciplinas poderão se organizar como as disciplinas tradicionais ou como o que ele chama "campos de estudos", que trabalhariam mais com a "interconceptualização", um exercício "revolucionário, sinóptico e transdisciplinar", de tal forma que proporcione à Ciência da Informação "desenvolver algum tipo de navegação conceitual que poderia, por sua vez, se desenvolver dentro de uma teoria sob a forma pós-moderna, numa rede centrada no conhecimento, sob a ótica do problema do uso do conhecimento em condições pós-modernas de informatização"(Wersig, 1993).

\section{INTERDISCIPLINARIDADE E CONCEITOS AFINS}

A interdisciplinaridade é inerente às ciências humanas e a discussão aqui apresentada tem por fundamento os conceitos de Japiassu (1976, p.29), no seu livro Intedisaiplinaridadee patdoga db saber, no qual o seu objetivo foi fornecer "certos elementos e instrumentos conceituais básicos para uma tomada de consciência sobre o lugar real de posição e tratamento dos principais problemas epistemológicos colocados pelas ciências humanas, do ponto de vista de suas relações interdisciplinares", o que significa o diálogo entre essas disciplinas.

Entre as motivações do projeto interdisciplinar, tanto intelectuais quanto afetivas, a primeira é criada pelo próprio desenvolvimento da ciência, isto é, a "necessidade de criar um fundamento ao surgimento de novas disciplinas". A interdisciplinaridade "se afirma como reflexão epistemológica sobre a divisão do saber em disciplinas para extrair suas relações de interdependência e de conexões recíprocas". Sua "grande esperança" é a "renovação e mudança no domínio da metodologia das ciências humanas" e seu "objetivo ideal" é "descobrir as leis estruturais de sua constituição e funcionamento -seu denominador comum". (Japiassu, 1976, p.54).

Sobre as origens do fenômeno interdisciplinar, Japiassu afirma que este tem dupla origem: "uma interna, tendo por característica essencial o remanejamento geral do sistema das ciências, que acompanha seu progresso e sua organização; outra externa, caracterizando-se pela mobilização cada vez mais extensa dos saberes convergindo em vista da ação". Por outro lado, sob o ponto de vista teórico e epistemológico as pesquisas interdisciplinares podem surgir de duas preocupações: "a primeira, relativa às estruturas e aos mecanismos comuns às diferentes disciplinas científicas que são chamadas a ingressar num processo de interação ou de colaboração; a segunda relativa aos possíveis métodos comuns a serem instaurados para as disciplinas cooperantes"(Japiassu, 1976, p.44).

Mas, conforme adverte Japiassu, o "fenômeno interdisciplinar está muito longe se ser evidente", ainda que o discurso interdisciplinar esteja presente nos ambientes de ensino, pesquisa e técnica, depois de muitos anos relegado ao ostracismo imposto pelo pensamento positivista. Pela interdisciplinaridade é possível 


\section{Invesigaaón Biblideedógica v. 12 No. 25 julio/ diciembre de 1998}

ultrapassar a dissociação de teoria e "ação informada", pois as pesquisas interdisciplinares não só "[...]postulam um ensino coordenado e integrado das ciências mas respondem às exigências da ação".(Japiassu, 1976, p.30)

Ao estudarmos interdisciplinaridade temos, obrigatoriamente, que nos reportar a conceitos próximos como multidisciplinaridade, pluridisciplinaridade e transdisciplinaridade, esta última, conforme veremos, uma etapa evolutiva da interdisciplinaridade, o que pressupõe 0 entendimento de disciplina.

Segundo Japiassu, disciplina é sinônimo de ciência, sendo mais empregada, no entanto, para designar o "ensino de uma ciência", ao passo que o termo ciência designa mais uma atividade de pesquisa. Assim, "uma disciplina deverá, antes de tudo, estabelecer e definir suas fronteiras constituintes. Fronteiras estas que irão determinar seus objetos materiais e formais, seus métodos e sistemas, seus conceitos e teorias". Conseqüentemente, disciplina e disciplinaridade são "a progressiva exploração científica especializada numa certa área ou domínio homogêneo de estudo". Disciplinaridade é por ele definida como "a explicação científica especializada de determinado domínio homogêneo de estudo, isto é, o conjunto sistemático e organizado de conhecimentos que apresentam características próprias nos planos do ensino, da formação, dos métodos e das matérias; esta exploração consiste em fazer surgir novos conhecimentos que se substituem aos antigos". (Japiassu, 1976, p.61 e 72)

Japiassu, por sua vez, toma como base um trabalho de E. Jantsch - Vers l'interdisciplinarité et la transdisciplinarité dans l'enseignement et innovation(1972)para ilustrar os conceitos de multidisciplinaridade, pluridisciplinaridade, interdisciplinaridade e transdisciplinaridade. Multidisciplinaridade é a "gama de disciplinas que propomos simultaneamente mas sem fazer aparecer as relações que podem existir entre elas", enquanto a pluridisciplinaridade é traduzida pela "justaposição de diversas disciplinas situadas geralmente no mesmo nível hierárquico e agrupadas de modo a fazer aparecer as relações existentes entre elas". (Japiassu, 1976)

Mas as disciplinas têm enfoques específicos e o real de cada uma é sempre reduzido ao ângulo de visão particular dos seus especialistas. Cada um deles adota sua forma de observar, representar e explicar sua realidade, própria da "dimensão do humano", portanto, sendo um visão monodisciplinar, é parcial e limitada da sua realidade. Conseqüentemente, essa visão unidisciplinar vai fragmentar o objeto e "reduzí-lo à sua escala própria". A interdisciplinaridade pode ser traduzida, "[...]antes de tudo, como o esforço de reconstituição da unidade do objeto que a fragmentação dos métodos indevidamente pulveriza"(Japiassu, 1976, p.66 e 67). Por outro lado, Japiassu identifica vários tipos de interdisciplinaridade, aqui apenas mencionados: interdisciplinaridade heterogênea, pseudo-interdisciplinaridade, interdisciplinaridade auxiliar, interdisciplinaridade compósita, interdisciplinaridade unificadora.(1976). 
Depois de definir os diversos tipos de interdisciplinaridade, Japiassu os reduz a apenas dois: interdisciplinaridade linear ou cruzada e interdisciplinaridade estrutural. A primeira na verdade não chega a ser interdisciplinaridade, e sim "uma forma mais elaborada de pluridisciplinaridade", porque as disciplinas permutam informações sem reciprocidade e não interessam diretamente a esta pesquisa. A segunda categoria se dá num processo interativo, quando disciplinas entram em diálogo, em reciprocidade e igualdade, ocasionando a fecundação "que dá origem, quase sempre, a uma nova disciplina: bioquímica, geopolítica, psicossociologia, por exemplo". Nesta interdisciplinaridade estrutural "há uma combinação das disciplinas, correspondendo ao estudo de novos campos de problemas, cuja solução exige a convergência de várias disciplinas, tendo em vista levar a efeito uma ação informada e eficaz". A esta questão voltaremos no final deste artigo, na convergência das ciências como a Ciência da Informação, a Comunicação e a Ciência da Computação.(Japiassu, 1976)

Para o exercício interdisciplinar Japiassu aponta quatro exigências. A primeira é essencial porque "[...]é indispensável que a interdisciplinaridade esteja fundida sobre a competência de cada especialista. 0 avanço da teorização interdisciplinar exige o domínio seguro das exigências epistemológicas e metodológicas comuns a todo conhecimento, bem como dos aspectos específicos e particulares das disciplinas humanas. A colaboração não deve jamais suprir as lacunas e carências de uns e de outros, nem mesmo as conseqüências do estado ainda precário em que podem encontrar-se algumas disciplinas[...]” A segunda exigência, já mencionada anteriormente, é do "reconhecimento, por cada especialista, do caráter parcial e relativo de sua própria disciplina, de seu enfoque, cujo ponto de vista é sempre particular e restritivo". Na terceira exigência é necessário "polarizar o trabalho interdisciplinar sobre pesquisas teóricas ou aplicadas, com vistas a resolver determinado problema social ou institucional com o concurso de várias disciplinas a ele concernentes[...]" E, finalmente, "a quarta exigência que se impõe ao trabalho interdisciplinar converte-se numa necessidade de ultrapassagem ou de superação. É preciso que os pesquisadores superem, mas sem negá-las, porque fazem delas etapas prévias indispensáveis, as outras modalidades de colaboração, quer dizer, todas as modalidades que não atingem uma integração propriamente dita das disciplinas, desde os conceitos, até os métodos"(Japiassu, 1976).

Quando Japiassu faz a distinção entre interdisciplinaridade e transdisciplinaridade enfatiza que a primeira caracteriza-se "pela intensidade das trocas entre os especialistas e pelo grau de integração real das disciplinas, no interior de um projeto específico de pesquisa"(Japiassu, 1976), enquanto a transdisciplinaridade, em citação de Piaget, equivaleria a uma etapa posterior e superior, "que não se contentaria em atingir interações ou reciprocidade entre pesquisas especializadas, mas que situaria essas ligações no interior de um sistema total, sem fronteiras estabelecidas entre as disciplinas"(Piaget apud Japiassu, 1976, p.75).

De acordo com o conceito de interdisciplinaridade adotado na pesquisa, neste artigo são identificados, sob o olhar de diferentes especialistas, as disciplinas com 
as quais a Ciência da Informação mantém laços interdisciplinares, procurando seguir uma certa cronologia, para melhor acompanhar a evolução dessas relações e compreendê-las no seu tempo, uma vez que paradigmas de trinta anos atrás podem ter perdido sua vigência e sido substituídos.

\section{A INTERDISCIPLIN ARIDADE NA CIÊNCIA DA INFORMAÇÃO}

Uma das primeiras observações a respeito de interdisciplinaridade da área é de Cuadra (1966, p.4), sobre a atenção que especialistas dedicam às suas áreas centrais de interesse, e a sua incapacidade de investir nas áreas periféricas, o que para ele "depende menos de interesse intelectual do que de tempo para buscar e ler literatura". A sua própria definição de interesses periféricos envolve "algum grau de risco calculado".

Entre os pioneiros na identificação de áreas interdisciplinares da Ciência da Informação destacam-se os já citados Mikhailov, Chemyi e Gilyarevskyi (1969) autores de trabalho publicado pela FID, em 1969, ressaltando a importância das relações da Ciência da Informação* com a Semiótica, a Psicologia e a Biblioteconomia. A primeira, por ser "[...]o estudo de diferentes sistemas de signos, com o propósito de descobrir seus princípios comuns e diferenças concretas, reveladas pela comparação desses sistemas[...]" portanto, é uma teoria geral de sistemas de sinais.(Mikhailov et al, 1969).

Na medida em que as atividades de informação constituem um "[...]caso particular de sinais da atividade do homem(isto é, atividades de geração e percepção de sinais)", se dá a contribuição da Semiótica para os fundamentos teóricos da Ciência da Informação.

Na divisão tradicional de semiótica pragmática, semântica e sintática 0 autor associou, a cada parte, os respectivos aspectos das atividades de informação e Ciência da Informação. 0 primeiro, de estudos pragmáticos de sinais, na medida de seu envolvimento com atividades do homem incluem "propriedades de sinais que têm significado para a Informática como inteligibilidade e não -inteligibilidade, essencialidade e não-essencialidade". 0 exemplo dado é o resumo, visto como uma tarefa pragmática, pois é um trabalho de condensação que deve ser inteligível e conter 0 essencial. Além de sistema de recuperação de informação, aperfeiçoamento do sistema de publicações primárias, indexação e outros. No entanto, os autores lamentam ser a pragmática a parte da semiótica menos desenvolvida (Mikhailov et al, 1969).

* Conforme já explicado, na União Soviética a Ciência da Informação é denominada Informática, termo assim utilizado, neste artigo, somente nas citações ipsis litteris de traduções do russo para o português. 
Estudos semânticos de sinais são formas de "designação de objetos e conceitos por meio de sinais (relação entre o signo e o objeto)" e correspondem não só a pesquisas sobre "as relações entre sistemas de sinais e a realidade, mas também entre diferentes sistemas de sinais que refletem a realidade". Portanto, todos os problemas semânticos ocupam, segundo os autores, um lugar de prioridade na Informática e os estudos do sentido (conteúdo) e significado (volume) dos sinais desempenham um papel decisivo na criação e análise de linguagens e sistemas de recuperação da informação, entre outros (Mikhailov et al 1969).

Análises sintáticas "tratam de prioridades formais e externas de sinais e suas combinações (relação de um signo com o outro)". A ssim, semiótica sintática diz respeito, particularmente, "a todos os aspectos da derivação formal de sentenças, de outras sentenças, somente na base de vínculos formais entre si, manifestados numa certa similaridade de estruturas externas dessas sentenças". Então, métodos sintáticos são importantes para a "mecanização" de atividades de informação. Para exemplificar as aplicações da Semiótica na Informática, Mikhailov e colaboradores identificaram projetos de pesquisa conduzidos pelo VINITI, entre os quais dois na área de Química: um sistema de codificação de estruturas de fórmulas químicas para "mecanização" e um serviço de recuperação factual "mecanizado" para uma Seção de Química Orgânica. (Mikhailov et al, 1969). Enfim, "[...]não será um exagero dizer que a interação da Semiótica com a Informática está exercendo uma forte, e em alguns casos decisiva, influência no desenvolvimento da própria Semiótica"(Uspenski apud Mikhailov et al, 1969).

A relação entre Ciência da Informação e Psicologia não é de menor importância para o desenvolvimento de uma teoria da Ciência da Informação. A Psicologia tem, "nos últimos anos" (final dos anos 60), apresentado um número de novas tendências, "algumas das quais estreitamente associadas aos problemas que estão sendo solucionados pela Informática". Este é o caso da Psicologia do Trabalho, Psicologia da Engenharia e Psicolingüística. A primeira surgiu no século 19 e se desenvolveu rapidamente nas últimas décadas e algumas das questões dessa área são relacionadas ao trabalho como o aumento da sua eficiência, as bases de racionalização de habilidades, medidas psicológicas para facilitá-lo e seleção e treinamento de pessoal. (Mikhailov et al, 1969).

A Psicologia da Engenharia é "mais fechada para os interesses da Informática" e abrange complexos estudos de sistemas homem-máquina, a aplicação do conhecimento ao comportamento humano para a concepção de sistemas e seus componentes, com o propósito de obter o máximo de eficiência com o mínimo de esforço para sua operação e serviço.(Chataris apud Mikhailov et al, 1969). Basta pensar nos sistemas de recuperação da informação para compreender 0 grande significado da Psicologia da Engenharia para resolução dessas tarefas .

O utra área de interesse para a Ciência da Informação é a Psicolingüística, que estuda "a natureza do discurso, a organização hierárquica do comportamento verbal, mecanismos do discurso e da percepção, problemas de semântica e de moti- 


\section{InvestigacónBiblicteedógica V. 12 No. 25 julio/ diciembre de 1998}

vação verbal e não-verbal, bem como tarefas práticas envolvidas na comunicação de massa e no discurso da cultura". A Psicolingüística é importante para a Ciência da Informação, na parte relativa "ao pensamento criativo e à geração e utilização de informação científica e técnica" e os resultados desses estudos muito contribuem "[...]para a compreensão dos mecanismos do processamento analítico-sintético da informação, incluindo sua codificação". Ramos da Psicologia são, conseqüentemente, relevantes para a elaboração de base teórica para a Informática (Leontiev apud Mikhailov et al, 1969).

É oportuno observar que no Brasil, estudos de usuários floresceram na década de 70, principalmente a partir de 1975, em função do mestrado em Ciência da Informação da UFRJ-Universidade Federal do Rio de Janeiro e IBICT- Instituto Brasileiro de Informação em Ciência e Tecnologia (Pinheiro,1983). Nessas pesquisas foi introduzida a técnica do incidente crítico, oriunda da Psicologia do Trabalho, e chegou a ser editada uma coletânea, no país, com o sugestivo título "A contribuição da Psicologia para o estudo de usuários da informação técnico-científica", incluindo um estudo sobre incidente crítico. (Pereira et al, 1980). A apresentação da publicação, não por mera coincidência, foi assinada pelo Professor José Augusto D ela Coleta, do Instituto de Seleção e Orientação Profissional ISOP, da Fundação G etúlio Vargas -FGV.

Entre os resultados empíricos da tese, da qual é oriundo este artigo, é oportuno mencionar a freqüência de periódicos utilizados por pesquisadores da área. Verificamos a presença, entre os mais freqüentes, de dois títulos de Psicologia e um de Lingüística: Applied Psychological Measurement, Journal of Experimental Psychology: Human Perception and Performance e Automatic Documentation and Mathematical Linguistics, além de outros menos freqüentes.

A respeito dos aspectos lingüísticos da Ciência da Informação, Foskett (1980) define a verdadeira comunicação como aquela que se refere "[...]à apreensão do significado, quando um esquema de conceitos estruturados é assimilado pela mente do receptor, que pode ajustar o esquema já existente em sua mente para incorporar dados novos", daí relativizar a influência da teoria da informação na Ciência da Informação e ressaltar Saussure, iniciador da teoria lingüística moderna e a Semiologia.

Segundo Foskett, as relações designadas por Gardin (apud Foskett, 1980) pelos termos paradigmático e sintagmático, de Saussure, tem "uma acentuada semelhança com o uso da análise de facetas", de Ranganathan* , o primeiro com as tabelas de classificação de dois pontos, e o segundo, com a análise das facetas para a classificação de documentos. Ranganathan é responsável pela evolução da

* Na associação feita com o trabalho de Ranganathan são citados

- Ranganathan, S. R. Prolegomena to library classification. Asia Publishing House, 3 rd. ed. 1970.

- Ranganathan, S. R. The Colon classification. Rutgers, The State Uniersity, 1965. 
classificação facetada para classificação analítico-sintética e categorias baseadas nas noções de personalidade, matéria, energia, espaço e tempo.

Foskett (1980) menciona a iniciativa da Cambridge Language Research University, em 1970, na aplicação de técnica de lingüística computacional na análise de freqüência de palavras em computador para classificação de palavras-chave, com resultados encorajadores na recuperação da informação.

Nesta mesma obra é citada uma importante Conferência sobre "Fundamentos do Acesso ao Conhecimento", realizada em 1965, em Syracuse, quando dois sociólogos americanos destacaram uma nova disciplina com "força diversificadora" e a necessidade de colaboração mais estreita entre acadêmicos e especialistas em informação.

Não há dúvida quanto às relações da Ciência da Informação e Lingüística na representação da informação. O Mestrado em Ciência da Informação da UFRJ-IBICT inclui uma linha de pesquisa nessa área, com estudos sobre Ranganathan, e durante alguns anos manteve entre professores do seu corpo docente um lingüista. Isto ocorreu há mais de quinze anos atrás e a partir de 1983 o Curso deixou de contar com essa colaboração. Relações interdisciplinares são relações de troca teórica e metodológica e, para que tal ocorra, é imprescindível clareza para identificar, entre as disciplinas envolvidas, onde se dá o encontro ou a interseção de duas área de conhecimento e esta era uma das dificuldades nos estudos de Ciência da Informação e Lingüística no Mestrado mencionado.

O utra relação interdisciplinar ressaltada por Mikhailov e colaboradores (1969) é com a Biblioteconomia, na qual Otlet aparece como responsável pela cisão entre atividade bibliográfica de biblioteca e o processo da D ocumentação, inicialmente considerada Ciência da Informação. Os autores discordam, apontando as restrições da D ocumentação, enquanto a Ciência da Informação seria mais abrangente.

Também Goffman (1970) aborda a interdisciplinaridade da Ciência da Informação com a Biblioteconomia e a Ciência da Computação e justifica a invasão da primeira nos currículos da segunda devido a três motivos. 0 primeiro, porque foram as bibliotecas as primeiras instituições que operam com informação a ingressarem na revolução automática do processamento da informação; segundo, a necessidade de formação profissional de bibliotecários e, em terceiro, a facilidade que estes parecem ter em aceitar outras disciplinas cuja "relevância é clara para eles". E, por considerarem que a Biblioteconomia ainda não definiu seus problemas, recorrem à Ciência da Informação para obter a respeitabilidade acadêmica que lhes falta, entre outros motivos, porque uma disciplina não pode se legitimar se é restrita a uma instituição como a biblioteca. Ele aponta quase os mesmos problemas na Computação, isto é, definição de problemas e busca de legitimidade acadêmica. Então, a Ciência da Informação não se restringe nem a uma nem a outra, e o seu desenvolvimento deve ser independente e transcender bibliotecas e computadores ou qualquer outro sistema físico que trate com informação, embo- 


\section{InvestigacónBiblicteedógica V. 12 No. 25 julio/ diciembre de 1998}

ra possa utilizar suas aplicações e se beneficiar tanto da Bibliotecomia quanto da Ciência da Computação.

Entre os autores que identificam áreas interdisciplinares com a Ciência da informação temos Borko (1968, p.3-5), mencionado no início deste artigo em histórico documento, no qual enumera as seguintes: Matemática, Lógica, Lingüística, Psicologia, Tecnologia de computador, Pesquisa de operações, Artes gráficas, Comunicação, Biblioteconomia e Administração.

Esta lista tem alguns pontos comuns com a de Merta (1968, p.38-39) do documento da FID 435, em que identifica os seguintes ramos da ciência nos quais a Ciência da Informação busca conhecimentos e métodos:

* Matemática e Lógica Matemática;

* Lingüústica e Semiótica;

* Cibernética e Teoria Matemática da Comunicação;

* Reprografia e Teoria do Conhecimento Automático; e

* Engenharia de Sistemas.

Para cada uma destas disciplinas é explicitado como se daria a colaboração com a Ciência da Informação.

A primeira, Matemática e Lógica Matemática seria útil para a análise de sistemas, algoritmização de operação de armazenagem da informação, recuperação e disseminação, métodos matemáticos, medida de eficiência dos sistemas de informação e compatibilidade.

A Lingüística e Semiótica são úteis "na criação de linguagens de recuperação da informação em sistemas de indexação e resumo automático de textos, tradução em máquina, unificação nacional e internacional de terminologia especializada, normalização (padronização) de registro de resultados de atividades criativas".

Cibernética e Teoria Matemática da Comunicação podem apoiar "na solução de problemas de recuperação da informação primária, minimizar o ruído de sistemas de informação, determinar os parâmetros de máquinas de informação especializada, programas-padrão de compiladores compatíveis para as principais operações de processamento de informação[...]" e devem solucionar problemas de inter-relação ótima entre instituições de informação central e periférica (Merta,1969).

Uma das disciplinas até então não apontadas entre as de relação interdisciplinar com a Ciência da Informação é a Estatística, em artigo de Harmon, não exatamente como idéia sua mas de autor por ele citado, Kitagawa (1971, p.238), que identifica "clara conexão" entre ambas, mas também com "todas aquelas como as ciências comportamentais, com notável tendência para a construção de modelos."

No início dos anos 80, importante obra de Machlup e Mansfield (1983) foi publicada, reunindo ensaios interdisciplinares sobre informação, de professores das mais renomadas universidades, inclusive o MIT, de áreas bem diversificadas, num 
total de 41 trabalhos, dos quais 38 são norte-americanos, dois da G rã-Bretanha e um do Canadá, distribuídos por nove seções do documento: a primeira sobre as relações e perspectivas da Ciência da Informação sob o ponto de vista de Ciência Cognitiva, o segundo sobre a ideologia, metodologia e Sociologia da Informática (Computação e Ciência da Informação), a terceira sobre as questões da história da inteligência artificial, a quarta sobre Lingüística e suas relações com outras disciplinas, a quinta abordando a Biblioteconomia e Ciência da Informação, suas divergências, competição e convergência, a seção 6 sobre Cibernética, a sétima, tratando dos 30 anos da teoria da informação, a oitava, sobre a teoria dos sistemas e sua relevância para problemas da Ciência da Informação e, a última, também sobre teoria de sistemas, conhecimento e Ciências Sociais.

A seção sobre Ciência da Informação, a quinta, apresenta ou trabalhos curtos, do tipo comunicação, ou seus autores foram analisados em outro capítulo da tese, como é o caso de Jesse Shera, cujo ensaio foi publicado após sua morte, em 1982, ou ainda, embora sob o título da interdisciplinaridade, não apresentam maior interesse para este artigo. Assim, nos deteremos no prólogo escrito por seus editores, Fritz Machlup e Una Mansfield, o primeiro, intelectual e economista vienense, radicado nos Estados Unidos e famoso por sua análise estatística da produtividade e distribuição de conhecimento nos EUA, marco da Ciência da Informação, conforme já vimos, e que faleceu em 1983, quando as atividades do projeto já estavam praticamente concluídas. E mencionamos, inicialmente e de forma breve, a apresentação de Miller e o prefácio de Una Mansfield, um relato da concepção do trabalho, de sua evolução e, principalmente, do papel de Machlup, em relação à obra e à Ciência da Informação.

Miller (1983, p.IX-X I) enfatiza a obsessão da América pela comunicação, justificada por seu sistema de governo, democrático e de livre economia e uma nova revolução industrial - a "indústria do conhecimento", conforme a denominou Machlup, "um dos primeiros a reconhecer e tentar caracterizar as conseqüências econômicas desta revolução[...]", na qual são importantes P\&D, a qualidade da pesquisa, dependente da educação que, por sua vez, é decorrência de periódicos e livros do "vasto sistema de comunicação dos Estados Unidos".

Segundo Mansfield (1983, p.XIII-XVI), o projeto inicial seria composto por 8 volumes, o primeiro sobre Ciências da Informação (no plural) e esta coletânea é o seu resultado. 0 objetivo era abordar disciplinas de informação que "exploram a inter-relação entre as numerosas disciplinas, metadisciplinas, interdisciplinas e subdisciplinas que tratam com informação como sua preocupação central ou periférica" e examinar as inter-relações entre as disciplinas cognatas ou complementares à Ciência da Informação (Machlup apud Mansfield, 1983, p. XIII).

O Projeto recebeu recursos da National Science Foundation para a New Y ork University e da Spencer Foundation e Earhart Foundation para a Princeton University. 


\section{InvesigaaónBiblictedóǵạ v. 12 No. 25 julio/ diciembre de 1998}

No prólogo intitulado "diversidade cultural em estudos de informação", Machlup e Mansfield (1983, p. 3-56) criticam a idéia de Snow* sobre as duas culturas, uma das ciências naturais, das mentes matemáticas e laboratórios, e outra daqueles que amam livros, intelectuais, na antiga dicotomia entre as chamadas ciências e humanidades, destacando o seu reconhecimento posterior das Ciências Sociais como uma espécie de "terceira cultura", assim como a possibilidade de milhares de culturas. Esta discussão nos remete a Solla Price, na caracterização de cientistas como "papirocêntricos" e tecnólogos como "papirofóbicos".

O s editores e organizadores da coletânea afirmam que nela estão presentes cerca de 30 ou 40 culturas e que as disciplinas incluídas podem ser constituintes de uma disciplina maior, com princípios comuns, especialidades ou disciplinas cognatas ou complementares de outros campos - relações interdisciplinares - e mencionam o estranhamento, por parte de alguns, quanto ao objetivo do Projeto. Machlup e Mansfield (1983, p.5) estão convictos da necessidade de derrubar barreiras e observam, em todos os ramos do saber, conflitos entre "especialização e interação, separatismo e unificação, isolacionismo e cosmopolitismo acadêmicos e, muito breve, fissão e fusão" .

Eles admitem a existência de cerca de 40 campos nos quais a informação desempenha um papel estratégico mas não é objeto de estudo, fenômeno na cena acadêmica que se iniciou nas três ou quatro décadas passadas, a partir dos anos 40, uma vez que a publicação data de 1983. A coletânea abarca cerca de 20 disciplinas ou subdisciplinas.

É interessante observar que eles consideram como possibilidade de identificação de novas especialidades a análise de citações, na produção de uma área, portanto, a Bibliometria.

Parte do prólogo é dedicado ao que é científico e não-científico, pesquisa e ensino, ciências formais e empíricas, além de conceitos e definições de várias disciplinas.

Especificamente sobre a Ciência da Informação, os autores esclarecem não estar envolvidos com qualquer controvérsia metodológica, "principalmente porque não existe concordância sobre seu objeto ou objetos[...] cientistas da informação tratam com matérias práticas e, por essa razão, com o mundo da experiência". E chamam a atenção para a confusão causada quando a Ciência da Informação é usada no plural para designar uma área mais ampla e que a informação, seu objeto de estudo, tem as mais diferentes interpretações, conforme vimos anteriormente (Machlup e Mansfield, 1983, p. 20).

Sobre as relações interdisciplinares da Computação com a Ciência da Informação não há "uma completa união" mas uma "co-habitação", a coexistência das

* Os autores citam duas obras de Charles P. SNOW, a primeira, "The two cultures and the scientific revolution", publicada em 1959 e, a segunda, em 1964, "The two cultures and a second look", p.66 e 70 . 
duas disciplinas, reconhecidas pelo uso do plural Ciências da Informação, com a intenção de abrigar disciplinas numa espécie de "guarda-chuva" curricular. Eles sugerem adotar Ciência da Computação e Ciência da Informação e reconhecem "boas razões" para essa junção, pois os primeiros têm interesse em informação e tendem a "ficar confinados ao seu papel nos sistemas de computação e envolver signos, símbolos e assim por diante (a abordagem semiótica) e seus processadores (a abordagem da informática)"(Machlup e Mansfield, 1983, p.20).

Quando analisam a Biblioteconomia e Ciência da Informação, Machlup e Mansfield perguntam se devem ficar juntas, fundidas num esforço de pesquisa completamente integrado. Eles esclarecem que na Biblioteconomia o foco da Ciência da Informação é diferente do da Ciência da Computação e tem sua origem no movimento da documentação dos anos 60, sobretudo nas Escolas de Biblioteconomia, mais voltadas a melhorar a "técnica, conteúdo intelectual dos registros e seu uso, aplicação de tecnologias nas funções tradicionais de bibliotecas". Embora eles não tenham evidências de que essa tecnologia tenha produzido, "radicalmente, novos meios de manipulação de estoques de conhecimento registrados em bibliotecas e outros materiais", por outro lado, admitem que os bibliotecários passaram a administrar centros de informação não-bibliográficos, participar de redes e na recuperação de bases de dados eletrônicos. Para os autores, a Ciência da Informação também pode ser uma disciplina independente, com abrangência mais restrita e sem ligação tanto com a Biblioteconomia quanto com a Computação. (Machlup e Mansfield, 1983, p. 22)

Mais recentemente, na Conferência de Tampere, algumas comunicações tiveram como tema questões interdisciplinares, sem contudo torná-las seu foco central. Entre todos, apenas um é especificamente devotado ao assunto, de autoria de Linda Smith(1992), com o seguinte título: "Interdisciplinaridade: abordagem para compreender a Biblioteconomia e Ciência da Informação como um campo interdisciplinar."

São adotadas duas linhas no desenvolvimento do trabalho, uma, de revisão e síntese de autores que estudaram a natureza interdisciplinar da área e, a outra, do próprio entendimento do conceito de interdisciplinaridade, centrado num documento de Klein (1992, p.254-262), que expande a análise até a multidisciplinaridade e transdisciplinaridade. A epígrafe do artigo, de Taylor, merece ser citada: "as ciências da informação são mais um território do que um país com limites definidos", embora discordemos do uso do plural para a área.

Smith (1992, p. 254), inicia o debate por uma reflexão sobre o tema da Conferência, abrangendo Biblioteconomia e Ciência da Informação, "deixando de fora a ridícula polarização Biblioteconomia X Ciência da Informação" e concordando com as observações de Rayward sobre a convergência dessas áreas, pois ambas estão "empenhadas em encontrar solução para o mesmo problema geral, a despeito da diferença de terminologia e orientação." O seu enfoque é voltado principalmente para a Biblioteconomia, considerando-a "somente uma perspecti- 


\section{8}

va no amplo conceito de informação" e podendo ser explorada outra como a da Ciência Cognitiva, Ciência da Computação, Inteligência Artificial, Lingüística, Cibernética, Teoria da Informação e Teoria dos Sistemas. No decorrer deste artigo, já ressaltamos as distinções básicas entre as duas áreas, ainda que reconheçamos as suas relações interdisciplinares.

Parte do trabalho de Smith (1992) é dedicado aos estudos que utilizaram a análise de citação como método para identificar áreas de interdisciplinaridade, na pressuposição de que "o assunto da literatura reflete o conteúdo do campo" (1992, p.255), o que, segundo Peritz (apud Smith, p. 255), pode distorcer o quadro se usada apenas a soma das citações como medida de abertura para outro campo.

Esses estudos usam fontes e categorias diversas, sendo ressaltada a dificuldade de interpretá-los pela ausência de detalhes, mas ainda assim considerados sugestivos. A análise de citação faz parte de estudos bibliométricos e no Brasil numerosas e significativas pesquisas foram desenvolvidas nessa linha, no mestrado em Ciência da Informação, da UFRJ e IBICT, tendo como iniciador Tefko Saracevic, professor do Curso nos seus primeiros anos e orientador das primeiras dissertações em Bibliometria.

Importante no trabalho de Smith é a inclusão de uma nova relação interdisciplinar que começa a aparecer de forma mais intensa, da Ciência da Informação e Comunicação, demonstrada em pesquisa de Borgman e Schment (apud Smith, 1992, p.255), tendo como objetivo "explorar modelos de convergência da Ciência da Informação e pesquisa em Comunicação", com a sugestão de fontes de dados que podem ser utilizadas para determinar a extensão dessa convergência. Essa relação interdisciplinar vai ser mais claramente discutida por Saracevic, autor com o qual finalizaremos este trabalho.

Os assuntos fronteiriços à Ciência da Informação podem ser mapeados pela Classificação do LISA - Library and Information Science Abstracts- e os resultados incluem: Comunicação, Computadores, Telecomunicações, O rganização e Administração, Conhecimento e saber, Educação, Museus, autoria, leitura, escrita, bibliografia, impressão, cópia, encadernação e publicação, comércio de livros, direito de empréstimo público e materiais audiovisuais. Smith (1992, p.256) chama a atenção para 0 fato de que há muito trabalho com apenas a enumeração de áreas interdisciplinares, sem nenhuma base, embora haja estudos empíricos também.

Verificamos que esta relação peca por misturar processo, matéria, disciplina, tipos de documentos etc. e por incluir assuntos do domínio da Biblioteconomia como direito de empréstimo público, cópia e encadernação, com disciplinas da Ciência da Informação. Portanto, se quisermos restringir essa lista a apenas disciplinas, temos apenas cinco: Comunicação, Telecomunicação, Organização e Administração, Educação, Museologia e Ciência da Computação. 
Considerando que os cientistas da informação não têm o domínio de tudo ou mesmo de algumas disciplinas, Machlup (apud Smith, 1992, p. 257) enumera, em também extensa lista, 23 disciplinas que, "dependendo do projeto", seriam essenciais: Lógica Formal e Simbólica, Semântica, Lingüística, Matemática Pura e Aplicada, Estatística e Teoria da Probabilidade, Teoria da Informação, hardware e software de computadores, Recuperação da Informação, Biblioteconomia, Cibernética, Engenharia de Sistemas, Teoria Geral de Sistemas, pesquisa operacional, Física, Eletrônica, Fisiologia, Epistemologia, Sociologia, Ciência Política, Economia, Psicologia, História e Filosofia da Ciência. Como não tivemos acesso ao documento original, ficamos sem saber se e inclusão das áreas é justificada e como se daria essa colaboração. Por outro lado, essa listagem já inclui disciplinas da própria Ciência da Informação, como é o caso da recuperação da informação.

Entre os vários autores que Smith cita, muitos já foram aqui estudados e, outros, até então estavam ausentes, como é o caso de Chambaud e Le Coadic(apud Smith, 1992, p.257), discutindo pesquisa básica em Ciência da Informação na França, "mistura" de Sociologia, Lingüística, Economia, Psicologia, Direito, Filosofia, Matemática, Ciência da Computação, Eletrônica e Telecomunicações.

De todos, a autora considera o de G reer (apud Smith, p,257), talvez "o mais elaborado modelo de interdependência interdisciplinar" , do qual fazem parte apenas quatro disciplinas: Engenharia da Informação, Organização e Administração da Informação, Psicologia da Informação e Sociologia da Informação. Este enfoque atenderia, em parte, às lacunas apontadas por Schrader (apud Smith, p.257). Q uanto à integração das "tradições de pesquisa mais fortes "da Sociologia da Ciência, História da Ciência, Filosofia do Conhecimento, Lingǘstica, estudos de Comunicação Científica, Teoria Geral de Sistemas e Economia do Conhecimento".

Apresenta particular interesse para a discussão de interdisciplinaridade, uma análise adotando o ARIST, feita por Afsharpanad (apud Smith, p.258) em tese de doutorado que chegou a um "core" de disciplinas, de acordo com a Classificação D ecimal de D ewey - CD D , o que talvez tenha limitado a categorização:

* Sistemas de Computação;

* Matemática Probabilística e Aplicada;

* Lingǘstica; e

Administração Geral

O utra análise relevante, de Mekhtiev (apud Smith, 1992, p. 259), é direcionada especificamente à literatura soviética, tão presente na área de Ciência da Informação pelo pensamento de Mikhailov e que revela as seguintes conexões com a Ciência da Informação, resultado coerente com os documentos aqui revistos, oriundos da antiga União Soviética: Lingüística, Cibernética, Tecnologia do computador, Matemática, Filosofia, Economia e História. 


\section{InvestigacónBiblicteedógia v. 12 No. 25 julio/ diciembre de 1998}

Sobre as relações entre Ciência da Informação e História é oportuno destacar que 0 ARIST de 1995 traz, pela primeira vez, uma revisão sobre História, Arquivos e Ciência da Informação, de autoria de McCrank.(1995)

Em estudo utilizando o Social Science Citation foram verificadas as relações da Ciência da Informação com as Ciências Sociais, cujos resultados indicam relações estáveis ou equilibradas com a Psicologia e a Sociologia, esta última, forte através da Sociologia da Ciência, "mais tênues" com a Psicologia, e de isolamento em relação a outros campos das Ciências Sociais, daí a Ciência da Informação não ter contribuição efetiva para o conhecimento das Ciências Sociais. (Small apud Smith p.259).

As pesquisas enfocam a interdisciplinaridade da Ciência da Informação especificamente com determinados campos, como Economia, Lingüística e Comunicação, tendo sido constatado o crescimento, no decorrer do tempo, da relação entre Ciência da Informação e Economia.

Sobre as relações com a Comunicação, Paislay (apud Smith, 1992, p.260) realiza uma análise de citações, cujos resultados demonstram que periódicos de Ciência da Informação estão isolados da Ciência da Comunicação e que a área "é fechada para certas disciplinas de pesquisa básica."

Nas conclusões, Linda Smith (1992, p. 260) reconhece as limitações de seu estudo "guia limitado para mapear o terreno" e a comprovação, por estudos empíricos, que existe, relativamente pequeno "empréstimo" de idéias, em contraste com listas indentificando disciplinas que podem ser úteis para a Biblioteconomia e Ciência da Informação, sendo " necessárias as evidências de estudos empíricos para explorar essas outras possíveis relações". Finalmente, ela conclui que há "[...]discrepância entre 0 que é dito (as muitas enumerações de caráter interdisciplinar da Biblioteconomia e Ciência da Informação, e o que é feito) se comparado ao isolamento da pesquisa em Biblioteconomia e Ciência da Informação de um corpo acadêmico de outras disciplinas."

Para que este campo contribua para outras disciplinas, há necessidade de muito mais estudos, de examinar os programas curiculares para verificar a sua interdisciplinaridade pois o que existe é uma rica mas dispersa literatura sobre interdisciplinaridade. "A discussão da pesquisa interdisciplinar, educação e prática em Biblioteconomia e Ciência da Informação pode ser enriquecida com as considerações de vários modelos derivados do exame da interdisciplinaridade de outros campos." (Smith, 1992, p. 263).

D epois da enumeração de tantas e distintas disciplinas que, em menor ou maior grau teriam interface com a Ciência da Informação, nem sempre fundamentadas, a abordagem da interdisciplinaridade é encerrada pelas lúcidas idéias da Saracevic (1992) expostas na Conferência Internacional de Tampere.

No item denominado evolução das relações interdisciplinares, Saracevic afirma que "os problemas básicos são de compreensão de informação e comunicação, suas manifestações e comportamento da informação humana, para tornar mais 
acessivel um desnorteador estoque de conhecimentos". Ele enfatiza a complexidade de tais estudos e, olhando os impasses tecnológicos, acredita que os problemas não podem ser resolvidos por qualquer outra disciplina.

A interdisciplinaridade da Ciência da Informação foi introduzida por diferentes experiências profissionais, mas nem todas trazem uma contribuição igualmente relevante, daí 0 autor concentrar o seu documento em apenas quatro disciplinas: (Saracevic, 1992, p. 12)

* Biblioteconomia;

* Ciência da Computação;

* Ciência cognitiva, incluindo inteligência artificial; e Comunicação.

Quando Saracevic chama atenção para os diferentes graus de contribuição interdisciplinar, torna mais clara a discussão e nos leva a criticar as longas listas de disciplinas com as quais a Ciência da Informação teria relação, muitas vezes definidas sem fundamentação, nem tampouco distinguir os níveis de contribuição, conforme observamos.

A primeira, com a Biblioteconomia, aqui tantas vezes mencionada, tem "[...]uma longa e admirável história de mais de três milênios", considerando sobretudo as bibliotecas como "[...]instituições sociais, culturais e educacionais indispensáveis[...]" e não somente uma organização em particular ou tipo de sistema de informação. Diferentemente da maioria dos autores analisados neste artigo, Saracevic tanto aponta as convergências quanto as divergências, entre os dois campos, identificando os pontos críticos dessa relação:

seleção e forma de definição de problemas;

questões teóricas colocadas e estruturas estabelecidas;

natureza e grau de experimentação, desenvolvimento empírico e conhecimento prático resultante/ competências decorrentes;

instrumentos e abordagens utilizadas; $\mathrm{e}$

natureza e intensidade das relações interdisciplinares estabelecidas e a dependência do progresso e evolução das abordagens interdisciplinares. (Saracevic, 1992, p. 13).

Esta distinção é evidenciada pelas agências de fomento que financiam as pesquisas em Ciência da informação, diferentes daquelas que financiam as de Biblioteconomia. Esta mesma diferença pode ser constatada nos eventos técnico- científicos, por exemplo, dos promovidos pelo Special Group on Information Retrieval (SIGIR), da Association of Computing Machinery, e os de associações de bibliotecários.

Essas discussões conduzem à conclusão, de Saracevic, de que Biblioteconomia e Ciência da Informação são campos distintos, com fortes laços interdisciplinares, não podendo sequer ser consideradas um caso especial uma de outra. A junção dos nomes numa só disciplina, considerando a "magnitude qualitativa" das diferenças aqui descritas, é injustificada e discutível. (Savacevic, 1992, p.14) 


\section{Invesigaaón Biblideedógica v. 12 No. 25 julio/ diciembre de 1998}

Podemos reforçar esses argumentos pela temática e conteúdo de comunicações apresentadas na 1a. e 2a. Reuniões Brasileiras de Ciência da Informação ou, mais recentemente, fazendo a mesma comparação com as pesquisas apresentadas nos Encontros de Pesquisa de Pós-G raduação em Ciência da Informação, cujos temas e enfoques são muito diferentes de trabalhos apresentados em congressos de Biblioteconomia e D ocumentação.

A base das relações entre Ciência da Informação e Ciência da Computação, ainda segundo Saracevic (1992, p. 14), é formada por aplicações de computadores e computação na recuperação da informação, assim como produtos, serviços e redes a estes associados. Entre ambas há uma relação de complementaridade, uma vez que a Ciência da Computação trata de processos algorítmicos que transformam a informação, e Ciência da Informação trata da "natureza da informação e sua comunicação para pessoas". Saracevic afirma que tem sido notado um número de cientistas da computação, fortemente engajados em P\&D de recuperação da informação, entre os quais destaca, como exemplo, Salton. Mas, por outro lado, há P\&D nessa área que não apresenta nenhuma relação com a Ciência da Informação.

Aspectos da Ciência da Computação não relacionados ao início da evolução da Ciência da Informação apresentam componente informacional significativo, associado à representação da informação, sua organização intelectual e ligações, busca e recuperação da informação, qualidade, valor e uso de informação: "sistemas especialistas, bases de conhecimento, hipertextos e sistemas relacionados, interfaces inteligentes, interação homem-computador e reutilização de software."

A terceira relação interdisciplinar, de acordo com Saracevic, ocorre com a Ciência Cognitiva, um dos mais novos campos interdisciplinares da última década, embora as questões do cérebro sejam debatidas desde a antigüidade. A Ciência Cognitiva emerge de um "amálgama de Psicologia, Filosofia, Antropologia, Neurofisiologia, Ciência da Computação e Lingüística". Lida com um vasto terreno de diferentes abordagens de questões do cérebro e da mente associadas às $\mathrm{Hu}$ manidades, Ciências da Vida, Ciências Sociais, Matemática Lógica e Engenharia e todas que têm interesse potencial para a Ciência da Informação. (Saracevic, 1992, p.16)

A Ciência Cognitiva é uma fonte de muita inovação em sistemas de informação como sistemas especialistas, hipertextos, bases de conhecimento, interfaces inteligentes e interação homem-máquina, sendo também fonte de "estruturas teóricas para cognição, na qual a informação é o fenômeno que desempenha 0 mais importante papel" (Saracevic, 1992, p.17).

E, por fim, as relações interdisciplinares com a Comunicação, termo, assim como a informação, com muitas conotações, em amplos e diferentes contextos e causador de mais confusão do que comunicação. 
A discussão envolve a relação entre informação como fenômeno e comunicação como processo, valiosa porque são essas relações entre ambos que vão determinar as relações entre Comunicação e Ciência da Informação.

Estudos acadêmicos sobre Comunicação são tão antigos como a Filosofia e a retórica de Aristóteles. Mais tarde filósofos estudaram, no discurso público, não só a arte da persuasão, mas também a natureza da comunicação e seus efeitos. Mas pesquisas em comunicação com estudos empíricos, coleção de dados, teste de hipóteses e outros instrumentos da ciência moderna, começaram nas primeiras décadas deste século, como resposta a muitas questões relacionadas a problemas de uma variedade de aspectos da sociedade industrial, tais como urbanização, migração, emergência da comunicação de massa, propaganda na 1a. Guerra Mundial. (Saracevic, 1992, p. 17-18)

Estudos acadêmicos de Comunicação envolvem distintos campos e Ruben (apud Saracevic, p.18) observa a sua concentração em problemas associados à comunicação humana, assim como o foco das pesquisas na comunicação ou na informação, por si mesmas, o que fragiliza a pesquisa de ambas por ser muito restrito e existirem muitas questões surgindo que precisam da atenção dessas disciplinas, num trabalho conjunto.

O utra constatação são os assuntos similares estudados por ambas, em diversos níveis, tais como "[...]lacunas de conhecimento, colégios invisíveis, difusão de informações, interação do homem com tecnologias da comunicação, comportamento na busca de informação, teoria da informação, teoria da comunicação, e sociedade da informação[...]”, temas que aparecem nos periódicos de ambos os campos. Também tem sido observado que alunos de Comunicação mudam para faculdades de Ciência da Informação e vice-versa, indicador da confluência de pessoas e de pesquisas da Ciência da Informação e da Comunicação. (Borgman e Schement apud Saracevic, 1992, p.18)

A mudança de curso de pós-graduação de Comunicação para Ciência da Informação, ou o contrário, também ocorre na Universidade Federal do Rio de Janeiro, entre a pós-graduação de Comunicação e de Ciência da Informação, fato ainda não estudado para verificação do grau em que ocorre e se tem se acentuado nos últimos anos. $\mathrm{O}$ que podemos afirmar, com base nos levantamentos da formação de alunos que ingressam no Mestrado em Ciência da Informação é que, nos últimos anos, Comunicação tem concentrado maior número de alunos.

Por outro lado, começam a surgir transferências ou mesmo ingresso de alunos oriundos da COPPE- Coordenação de Pós-G raduação de Engenharia, da UFRJUniversidade Federal do Rio de Janeiro.

E, finalmente, um artigo brasileiro de Pinheiro e Loureiro(1995), no qual os autores traçam um mapa da Ciência da Informação e identificam 12 disciplinas científicas e tecnológicas e as respectivas áreas interdisciplinares, após sintetizarem a evolução conceitual do campo, a natureza da informação, objeto de estudo e suas dimensões social e tecnológica. 
Conforme advertência dos próprios autores, o diagrama reflete o pensamento de um grupo de estudos brasileiro, num determinado momento. Certamente o resultado está estreitamente relacionado à história do mestrado em Ciência da Informação, da UFRJ e IBICT, até porque o conjunto de disciplinas ou subáreas da Ciência da Informação reúne grandes temas ou linhas de pesquisa desse programa de pós-graduação, o primeiro, no Brasil e na América Latina, devotado à Ciência da Informação e que desde os seu início tem presença permanente de alunos de outros países da América Latina e Caribe.

E mbora o presente artigo tenha por objeto a interdisciplinaridade, é pertinente envolver na discussão aspectos disciplinares, isto é, a constituição epistemológica da Ciência da Informação, da qual decorre a interdisciplinaridade.

Algumas disciplinas presentes na figura são típicas da história do Curso, herança dos primeiros professores estrangeiros, como a Bibliometria, iniciada por Tefko Saracevic, conforme já destacado, e avaliação de sistemas de informação, área em que o professor Lancaster é conhecido mundialmente.

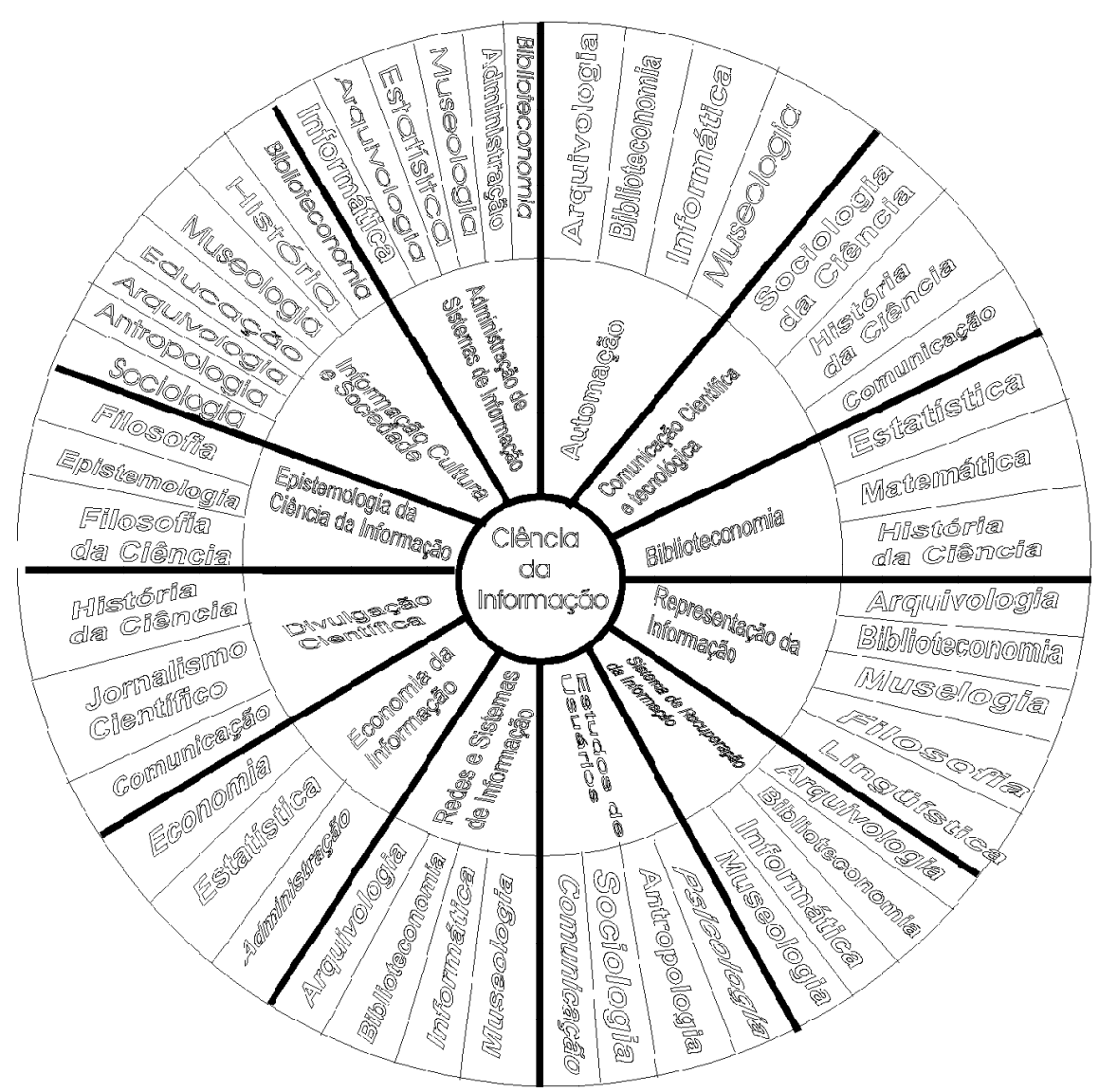

Fonte: Pinheiro, Lena Vania Ribeiro, Loureiro, José Mauro Mattheus. Traçados e limites da Ciência da Informação. Ciência da Informação, Brasília, v.24, n.1, p.42-53, jan./jul.1995. 
Mas os professores brasileiros nunca foram indiferentes à outra corrente de pensamento liderada por Mikhailov, tanto que a comunicação científica esteve sempre entre as suas preocupações, assim como representação da informação e organização do conhecimento.

Numa análise mais geral e por conhecimento de causa, o diagrama apresentado denota harmonia entre as duas faces da Ciência da Informação, tecnlógica e social, na sua universalidade, e certamente nas suas tendências nacionais e locais.

Q uanto às áreas interdisciplinares nele incluídas, aparece a maioria das citadas por autores estrangeiros, cujos trabalhos foram estudados neste artigo.

Três áreas surgem como mais fortes nas suas relações de interdiscipliaridade com a Ciência da Informação: Biblioteconomia, Arquivologia e Museologia. Excetuando a primeira, com a qual a interdisciplinaridade é reconhecida pela quase totalidade dos estudiosos, as outras duas têm sua presença acentuada provavelmente por um equívoco entre interdisciplinaridade e aplicações, o que será explicitado nas considerações finais deste artigo.

A Informática foi incluída na vinculação a quatro disciplinas da Ciência da Informação, seguida de um conjunto de áreas relacionadas três vezes, Comunicação, Estatística e História da Ciência, e por um grupo identificado duas vezes nas relações interdisciplinares: Administração, Antropologia, Filosofia e Sociologia. As demais disciplinas, num total de dez, foram assinaladas apenas uma vez: Economia, Educação, Epistemologia, Filosofia da Ciência, História, Jornalismo científico, Lingüística, Matemática, Psicologia e Sociologia da Ciência.

Conforme podemos verificar, há relações interdisciplinares identificadas com uma determinada área, Filosofia da Ciência, e uma de suas subáreas, a Epistemologia.

\section{MUTAÇÕESE HORIZONTES DA INTERDISCIPLINARIDADE NA CIÊNCIA DA INFORMAÇÃ O}

Antes de abordarmos as principais questões sobre a interdisciplinaridade da Ciência da Informação, não podemos deixar de mencionar os aspectos que, direta ou indiretamente, vão influenciar o traçado do território interdisciplinar da área: sua origem, natureza, objeto de estudo, a informação, e disciplinas que a constituem.

A Ciência da Informação tem dupla raiz: de um lado a Documentação e, de outro, a recuperação da informação. Na primeira o que importa é o registro do conhecimento científico, a memória intelectual da civilização e, no segundo, as tecnologias de informação. Ciência e Tecnologia foram os elementos fertilizadores e propulsores de seu nascimento, fruto do crescimento de equipes científicas, do aumento do número de cientistas e pesquisadores, e da aceleração de pesquisas, portanto, de conhecimento, além dos desenvolvimentos tecnológicos, es- 


\section{6}

forços decorrentes sobretudo da 2a. Guerra Mundial. E as tecnologias, principalmente os computadores, a fazem emergir.

D a mesma forma, na estruturação interna na Ciência da Informação, ou interdisciplinaridade interior, uma única disciplina pode tender à abordagem social ou tecnológica. Um bom exemplo é sistemas de informação, cujo estudo comporta tanto os aspectos tecnológicos de automação e gerenciais, de planejamento e administração do sistema, quanto estruturais, se estudadas teorias como a teoria geral de sistemas, ou de representação, que incluem os processos de descrição bibliográfica e indexação.

O campo de aplicação foi-se expandindo, passando de informação científica original para tecnológica e industrial, até chegar à informação em Arte. Assim é que a informação de que trata hoje, esta área, não mais está confinada à Ciência, 0 que pode se estender mais ainda com a Internet.

É pois, do conjunto de disciplinas que compõem a Ciência da Informação que pode ser pensada a interdisciplinaridade, isto é, de que forma e como outros campos do conhecimento contribuem para a Ciência da Informação, com seus conceitos, princípios, técnicas, métodos e teorias e, inversamente, a Ciência da Informação para os demais campos do conhecimento. Em estudos e pesquisas sobre interdisciplinaridade há o reconhecimento de que a Ciência da Informação incorpora muito mais contribuições de outras áreas, do que transfere para essas um corpo de conhecimentos gerados dentro de si mesma.

Q uanto à interdisciplinaridade, a primeira observação relativa à questão diz respeito à literatura sobre 0 assunto, além de métodos e técnicas adotados nos estudos.

Alguns trabalhos elencam disciplinas com as quais a Ciência da Informação mantém inter-relação, às vezes até numerosas, sem explicitações, aprofundamento ou fundamentação teórica que as justifique.

Outros adotam análise conceitual ou utilizam a Bibliometria, como a tese de Afsharpanah e pesquisas citadas por Linda Smith, aplicando análise de citações, cocitações, tendo como base o Social Science Citation Index .

Aparecem, ainda, estudos orientados a programas de pós-graduação em Ciência da Informação, cujo exemplo é o artigo de Pinheiro e Loureiro. Hoje, repensando esse resultado, constato uma distorção, já apontada neste artigo, pela não diferenciação entre interdisciplinaridade e aplicação. Na Ciência da Informação, as aplicações (contextos, áreas, setores e organismos) isto é, a informação científica, tecnológica, industrial ou artística, ou a aplicação em campos do conhecimento, como na Medicina (informação em Medicina), se mesclam com a interdisciplinaridade propriamente dita. É fundamental esclarecer que uma área de aplicação pode apresentar contribuições interdisciplinares, como é o caso da Biblioteconomia, que também é uma aplicação, por exemplo, em Automação de Bibliotecas enquanto, ao mesmo tempo, contribui para a representação da informação, com técnicas de catalogação, classificação e indexação. 
Por outro lado, trabalhos incluídos no presente artigo foram analisados na sua estrutura, utilizada como indicador de áreas interdisciplinares. Este é o caso da volumosa e importante coletânea "Interdisciplinary messages", organizada por Machlup e Mansfield, ou o Library and Information Science Abstracts -Lisa, abordado no artigo de Smith. Nesses dois exemplos, na realidade instrumentos indiretos para identificar áreas interdisciplinares da Ciência da Informação conseqüentemente, aparecem assuntos, e não exatamente o que corresponderia a ciências, disciplinas ou campos do conhecimento.

Na rede ou teia de interdisciplinaridade da Ciência da Informação podemos vislumbrar certas mutações e tendências ao longo do tempo ou a predominância de algumas disciplinas em correntes oriundas de determinados países, em especial os Estados Unidos e a antiga União Soviética, muito presentes no alvorecer e nas discussões teórico-conceituais da Ciência da Informação, o primeiro, onde a disciplina foi formulada pela primeira vez, no Georgia Institute of Tecnology, em 1962, e país dos maiores avanços da área.

Nos Estados Unidos, no início a Ciência da Informação está mais fortemente voltada às tecnologias de informação incorporadas, inclusive, no título de uma das mais importantes publicações da área, o ARIST- Annul Reviewof Infomation Säence and Tehndogy. Lá, as relações interdisciplinares são fortes com a Ciência da Computação, Cibernética e Engenharia de Sistema, e também com a Biblioteconomia, enquanto na União Soviética, principalmente pelas idéias de Mikhailov, há concentração em áreas como a Psicologia, Lingüística, Semiótica, Biblioteconomia, ainda que os autores soviéticos também incluam a tecnologia de computadores e a Cibernética, como Mekhtiev e colaboradores.

Por outro lado, Borko, nos Estados Unidos, já em 1968 reconhece a importância tanto da Lingüística quanto da Semiótica, ao lado de outros campos do conhecimento.

Os estudos de interdisciplinaridade da Ciência da Informação freqüentemente abrangem teorias, e não propriamente áreas, especialmente a teoria da informação ou teoria matemática da comunicação, de Shannon e Weaver, e a teoria geral de sistemas-TG S, de Bertalanffy.

Em termos de disciplinas, na década de 60 e 70 a Lingǘstica e a Psicologia são muito citadas, mas a segunda parece ter perdido intensidade no reconhecimento de sua interdisciplinaridade com a Ciência da Informação, pelo menos não é tão apontada, hoje, pelos autores da área, enquanto a Lingüística está muito atrelada à tecnologia em indexação automática e Lingüística computacional.

Há disciplinas menos presentes entre as consideradas interdisciplinares à Ciência da Informação, entre as quais Estatística, Administração e Economia, todas três de fato relevantes, a primeira principalmente para a Bibliometria e estudos de uso, a segunda, no planejamento e administração de unidades de informação em geral (bibliotecas, centros, sistemas, redes e serviços) e a última, em avaliação de custo/ beneficio e, ultimamente, nos aspectos da globalização. 


\section{Invesigaaón Biblideedógica v. 12 No. 25 julio/ diciembre de 1998}

Contrariamente, a Biblioteconomia e a Ciência da Computação aparecem no seu diálogo com a Ciência da Informação, desde os seus primórdios, e se mantêm até hoje, num exercício interdisciplinar permanente. Essas relações, tão fortes, fazem com que ambas sejam muitas vezes incorporadas ao nome Ciência da Informação ou com esta sejam confundidas, sobretudo na década do aparecimento da Ciência da Informação, de 60.

Ainda hoje, a nomenclatura da área, embora consolidada como Ciência da Informação, principalmente nos Estados Unidos, algumas vezes tem ao seu nome acoplada a Biblioteconomia, o que pode ser decorrência inclusive dos laços originais com a D ocumentação. No entanto, esta posição parece ser equivocada, na medida em que a D ocumentação surge da cisão com a Biblioteconomia, portanto, nasce da divergência. Isto não significa negar as relações interdisciplinares com esta disciplina, mas afirmar a independência científica da Ciência da Informação, com seu próprio estatuto científico.

É oportuno lembrar que o conceito de Informática foi elaborado pela primeira vez por D reyfus, em 1962, mesmo ano da formulação oficial da Ciência da Informação e que as duas, juntamente com a Comunicação, são disciplinas contemporâneas, afloram quase simultaneamente.

A Ciência da Informação, a Comunicação e a Ciência da Computação formam um triângulo disciplinar altamente dependente da nova ordem tecno-cultural, principalmente as duas primeiras, o que poderá, no futuro, levar à formação de uma disciplina com características transdisciplinares, do tipo Infocomunicação.

Por outro lado, resultados desta pesquisa identificam uma tendência à denominação departamental de estudos de informação, o que talvez traduza a reunião de disciplinas cujo objeto de estudo seja a informação, na estrutura universitária.

Há, ainda, um conjunto intermediário de muitas disciplinas que flutuam em níveis de intensidade que variam de acordo com a abordagem de cada pesquisa, e outras que parecem ter se tornado mais frágeis, no decorrer do tempo, mas sua identificação depende de pesquisas nesse sentido. Porque a Ciência da Informação tem como nascente o processo de comunicação e informação que se desenvolve em diferentes territórios: científicos, tecnológicos, educacionais, sociais, artísticos e culturais, portanto, múltiplos contextos e condições experimentais.

O bservamos, nos resultados desta pesquisa, que a tendência inicial de privilegiar aspectos tecnológicos, a máquina pela máquina, foi se diluindo, ou numa metáfora com a terminologia da área, o "hard" foi se tornando "soft", e as disciplinas originária e fortemente tecnológicas passaram a ser estudadas em função dos seus impactos na sociedade e na relação com o homem, na tentativa de um diálogo amigável, busca de interfaces e quebra de arestas.

O objeto de estudo da Ciência da Informação, a informação, flutua entre sombra e luz, na complexidade não somente de seu processo de criação, mas na sua passagem para conhecimento e, sobretudo, num processo histórico mais amplo e 
não menos complexo, de profundas e radicais transformações da sociedade da informação ou da tecnocultura.

A Ciência da Informação, gestada sob o signo da guerra e herdeira da tecnologia, parece buscar a reconciliação com o humanismo quase perdido, uma das fontes de seu nascimento, e caminhar, juntamente com a Comunicação e outros campos do conhecimento contemporâneos, para a constituição de uma nova categoria de ciências sociais - as ciências tecno-culturais.

\section{REFERÊNCIAS BIBLIOGRÁFICAS}

A.F SHARPANAH, Shahrokh. Intedisaiplinary structure of infomation sience Dissetation Abstrads Intemational, 45, 1227A. D octoral dissertation, Case Western Reserve University, 1984.

BACHELARD, G aston. A Filosofia dbnãa Filosofia donovoesṕnitodientífico 4 ed. Lisboa: Editorial Presença, 1987. 136 p.

BELKIN, Nicholas J., Robertson, Stephen E. "Information Science and the phenomena of information". JASIS, v.27, n.4, p.197-204, July-August 1976.

BORG MAN, C. L., Schement, J. R. Informationsienceand communication rearch In: Pemberton, J. M., Prentice, A. E. eds. Information Science: the interdisciplinary context New Y ork, Neal-Schuman, 1990. p.42-59.

BORK O. H. "Information Science: what is it?" AmerianDoamentation v.19, n.1, p.3-5, Jan. 1968.

BRO OKES, Bertram. C. "The foundations of Information Science". Part I: Philosophical aspects. Jaumal of Information Säence, v.2, p.125-133, 1980.

- -. "The foundations of information Science". Part II. Q uantitative aspects: classes of things and the challenge of human individuality. Jamal of Information Saience, v.2, p.209-221, 1980.

- -. "The foundations of information Science". Part III. quantitative aspects: objective maps and subjective landscapes. Jaumal of Infomation Saienee v.2, p.269-275, 1980 .

BRO OKES, B. C. "The foundations of information Science." Part IV Information Science: the changeing paradigm. Jaumal ofInfomationSaiene, v.3, p. 3-12, 1981. 
- -. "The fundamental equation of Information Science". In: Information Science its scope, djets of rearch and prodens Moscow, VINITI, 1975 (FID 530).

CHAmBAUd, S., Le Coadic, Y. F. "Basic research in information science" in France Infomation Processing\& Management, v.23, p. 411-418, 1987.

CHATARIS, A. Algumas quinõos sobreEngrnhania, Psicdogia esistema. Psicdoga da engenharia e psicdoga Moscow: Progresso, 1964 p.86-128 apud Mikhailov, A. I., Chemyi, A. I., G ilyarevskii, R. S opus cit p.19 Tradução da referência do russo para o português pela Prof. Gilda Braga.

CROS, R. C.,Gardin, J. C., Levy, F. Láutomatisationdesreeheches do ametaires: un modlegétal, lesYNTOL. Paris: G authier-Villars, 1964.

CUAD RA, Carlos A. "Introduction to ADI Annual Review". In: Annual Review of Ifomation Saence and TechndogyARIST, v.1, p.1-14, 1966.

FO SKETT, D . J. “Informática”. In: Ciêniada InfomaçãoauInfomá tica? Org. Hagar Espanha Gomes. Rio de Janeiro, Calunga, 1980. p.9-51 Artigo originalmente publicado no Journal of D ocumentation, v.26, n.4, p.340-69, Dec. 1970.

- -. "Ciência da Informação como disciplina emergente: implicações educacionais". In: Ciêna da Informação au Infamática? O rg. Hagar E spanha G omes. Rio de Janeiro, Calunga, 1980. p. 53-69.

GARDIN, J.-C. Syntol. Rutgers, TheStateUnivesity, 1965.

G OFFMAN, William. Information Saience disaipline or disappearence Aslib Proceedings, v.22, n.12, p.589-596, D ec. 1970.

GREER, R. C. "A model for the disciline of information science". In: Adleitne, H. K. ed. Intellectual founsdations for information professionals Boulder, CO: Social Science Monographs, 1987. p.3-25.

JANTSCH, E . "Vers l'interdisciplinarité et la transdisciplinarité dans l'enseignement et innovation". In: OCDE/ CERI. L' interdis àplinaité prodlèmes d'enseignenent $\notin$ dereherchedans les univesités Paris: 1972.

JAPIASSU, Hilton. Intedisciplinaridadeepatdoja dbsaber. Rio de Janeiro: Imago, 1976. 221 p. (Série Logoteca) 
JAPIASSU, Hilton. Introdurãão ao pensamento qpistemdóġca 2 ed. Rio de Janeiro: Francisco Alves, 1977, 202.

KitagaWA, T. "Information Science and its connection with Statistics". Fukuoka, Japan: Research Institute of Fundamental Information Science, Kyushu University, 1968 apud Harmon, Glynn. "On the evolution of Information Science". Jaumal of theAmeicanSoiedyforInformation Saiene, v.22, n.4, p.235-241, 1971.

K LEIN, J. T. Interdisalinanity: history, theary, andpradice D etroit, MI: Wayne State University Press, 1990.

Leontiev, A. A PsicdingüsicicaPublicaçãodaCiênaia Moscou: 1967. 18p. Tradução da referência do russo para o português pela Prof. Gilda Braga.

MACHLUP, F. "An economist's reflections on an Institute for the Advanced Study of Information Science". Jamal of theAmerian Socieyfor Information Saiene, v. 30, p.111-113, 1979.

MACHLUP, Fritz, Mansfield, Una, ed. Thestudy of information: intedisciplinary messages New Y ork, John Wiley \& Sons, 1983. 743p.

- -. Prologue. In: Machlup, Fritz, Mansfield, Una, ed. Thestudy ofinfomation: intedisaipinary messages New Y ork, John Wiley \& Sons, 1983. p.3-56.

- -. Application totheNational Saiencefoundation 1979. p. XIII.

MANSFIELD, Una. Preface. In: Machlup, Fritz, Mansfield, Una, ed. Thestudy finfomation: intedisciplinarymessages New Y ork, John Wiley \& Sons, 1983. p.XIII-XVI.

MCCRANK, Lawrence J. "History, archives and Information Science". Annual Reiewof Information Saieneand Tehndogy, v. 30, p.281-382, 1995.

MEKHTIEV, D . M. et al. "Using an index of cited literature to analyse the current state and trends of Information Science". AutomaticDoamentationand Mathematical Linguistics, v. 11, n.1, p.49-59, 1977.

MERTA, A. "Informatics as a branch of science". In: FID/ RI. Intemational Fede rationforDoomentation StudyCommitteeResenchonTherietical BasisofInformtion On theretical of Infomatics Moscow: All-Union for Scientific and Technical Information, 1969 (FID 435). p.7-24.

Mik HAILOV, A. I., Chernyi, A. I., G ilyarevsky, R. S. "Informatics: its scope and methods". In: FID/ RI. Intemational FeekrationforDoumetation StudyCo mitteeReserch on Theortical problems of Infomatics. Moscow, ALL-Union for Scientific and Technical Information, 1969. (FID 435) p.7-24. 
MiLLER, G eorge A. "Foreword". In: Machlup, Fritz, Mansfield, Una, ed. The study of infomation: intedisaplinary messages New York, John Wiley \& Sons, 1983.p.IX-XI.

PAISLEY, W. "The convergence of communication and information science". In: Edelman, H. ed. Libranesandinfomationsience in theddranicage Philadelphia, PA: ISI Press, 1986 p.122-153.

Pereira, Maria de Nazaré F., Espanha, Hagar E., Pinheiro, Lena Vania Ribeiro, Oliveira, Regina Maria S. de. "A aplicação da técnica do incidente crítico em estudos de usuários de informação técnico-científica". In: A contribuiçãoda Psicdoga para os estudodbsusuániosdainformacãoténicodentífica $\mathrm{O}$ rg. e trad. de Ha gar Espanha G omes. Rio de Janeiro, Calunga, 1980. p.43-71.

PIAG ET, J. Tandancespinipalesdelareherhedanslessiencessoialese humaines Paris, Mouton/ UNESCO, 1960.

PInHeIRo, Lena Vania Ribeiro, Loureiro, José Mauro Mattheus. Traçados elimites da Ciênia da Infomaçãa Ciênia da Infomaçãa, Brasilia, v.24, n.1, p.42-53, jan./ jul.1995.

- - A Ciênia da Informaçãoentresanbra eltz: donńnioq̣istemdógicoe campo intedisaiplinar. Rio de Janeiro, UFRJ/ ECO, 1997. Tese (D outorado em Comunicação e Cultura).

- -. Usuánioinfomaçãa ocontextodaCiêna edaTemdoga Rio de Janeiro: LTC-Livros Técnicos e Científicos, IBICT, 1983. 66 p.

ROBERTS, Norman. "Social considerations towards a definition of Information Science". Jamal of Doumetation v. 32, n. 4, p.249-57, Dec. 1976.

RUBEN, B. D . Commmicationandhumanbehavior. New York, MacMillan, 1984.

SARACEVIC, Tefko. "Information Science: origin, evolution and relations". In: Vakkari, Pertti, Cronin, Blaise, ed. Conceptions of Library and Information Science: historical, empirical and theoretical perspectives. Proceedings of the Intemational Confe rencehddfortheceldration of 20thA miversary of theDepartmet of In formation Studies University of Tampere, finlância, 26-28, August 1991. London, Los Angeles: Taylor Graham,1992. p.5-27.

SCHRADER, A. M. "In search of a name: information Scienceand its conceptual antecedents". Library \& Information SäenceRe serch v.6, p.227-271, 1984. 
SMALL, H. "The relationship of information science to the social sciences: a cocitation analysis". Infomation Processing \& Managanent, v.17, p 39-50, 1981.

SMITH, Linda. "Interdisciplinarity: approaches to understanding library and information Science as an interdisciplinary field". In: Vakkari, Pertti, Cronin, Blaise, ed. Conceptions of Library and Information Science: historical, empirical and theoretical perspectives. Proweengs of the Intemational Conferencehddfor the ddaration of 20thAnniversary of theDepartment of Informe tionStudies University of T ampere, finlância, 26-28, August 1991. London, Los Angeles: Taylor G raham, 1992. p.253-267.

TAYLOR, Robert. "Professional aspects of information science and technology". In: ARIST- Annul reviewofinfomation SienceandTehndogy, v. 1, p.1540, 1966.

USPENSKI, V. A. FragnentosdemanuscitosdbProfessorV . A. Uspendki sdbreosig nificadb da Semiótica para a infomação centífica Tradução da referência do russo para o português pela Prof. Gilda Braga.

Vledul, G. E. Semiótica. Cadeno Cibemética. As palavas espeeializadas 1967 p.370. Tradução da referência do russo para o português pela Prof. Gilda Braga.

WERSIG, Gernot. "Information Science: the study of postmodern knowledge usage". Infomation Prowsing \& Managment, v.29. n.2, p. 229239, 1993. 